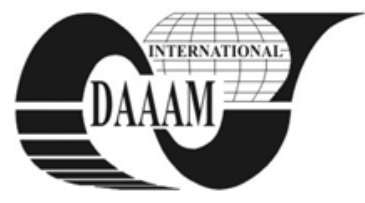

Annals of DAAAM for 2011 \& Proceedings of the 22nd International DAAAM Symposium, Volume 22, No. 1, ISSN 1726-9679 ISBN 978-3-901509-83-4, Editor B. Katalinic, Published by DAAAM International, Vienna, Austria, EU, 2011 Make Harmony between Technology and Nature, and Your Mind will Fly Free as a Bird

\title{
IMPLEMENTATION OF AN ERGONOMICS PROGRAM IN THE MANUFACTURING COMPANIES
}

\author{
STRAKOVA, N[ada] \& HATIAR, K[arol]
}

\begin{abstract}
Systematic introduction of an ergonomics program should be the standard for manufacturing companies. Ergonomics program is one of the tools for sustainable improvement of the efficiency of human labor in business. The article describes the results of an investigation of real integration of ergonomics program and interconnection with other processes in the manufacturing companies in Slovakia and in some selected countries.
\end{abstract}

Key words: ergonomics program, ergonomics analysis, process management, research

\section{INTRODUCTION}

In the developed countries, the experience of the ergonomics program provides the creation of suitable working conditions and working environment, removing all negative influences, whether psychological or physical in safety and prevention of occupational risks, and a significant reduction in associated costs to society (Cohen L.C., 1997). Finally, I must also mention the satisfaction of employees who are not willing to avail themselves of the program, although it is a long-term investment and highly refundable.

In developing countries, where levels of law enforcement are low, the efficiency of human labor is generally achieved at the expense of their employees through low wages, high job growth and a low level of care in protecting health. In developed countries, where the effectiveness of human labor are achieved through an Ergonomics program that allows solving problems systematically and simultaneously focuses on workers' health and cost benefits (Hatiar K., 2010).

\section{IMPLEMENTATION REVIEW}

Since the application of Ergonomics program (EP) is a common practice in developed countries it has been surveyed to determine the application of ergonomics program in Slovakia and abroad. To analyze the state of implementation of contemporary ergonomics program in business practice, questionnaire methods have been used and the target groups were manufacturing companies.

The questionnaire contained seven questions, which was to determine whether businesses have introduced ergonomics programs and its links with other processes in the enterprise (Grasseová M., 2008). At the beginning of exploration, targets have been set:

Detect.

- whether companies have implemented ergonomics programs

- or ergonomics program is introduced as a separate process or as part of occupational safety and health $(\mathrm{OSH})$ programs,

- whether the companies have developed ergonomic teams that performed the analysis,
- whether the companies perform regular ergonomics analysis,

- how to implement an ergonomics program,

- whether the ergonomics program is linked to other processes,

- how they see the benefits of implementing an ergonomics program.

\section{SURVEY RESULTS}

Of the 898 questionnaires sent out, 73 were returned, which is $8.12 \%$ were contacted mostly domestic companies but also foreign. Completed questionnaires not returned at this stage are mainly from companies from the Czech Republic, Slovakia and Cyprus.

Of the returned questionnaires 51 were from SR (from 73, representing 69.9\%), 16 from CR (21.9\%), 6 from Cyprus $(8.2 \%)$. A substantial part of the questionnaires was from medium and large enterprises. For better visibility of the participants, states are shown graphically in figure number 1 .

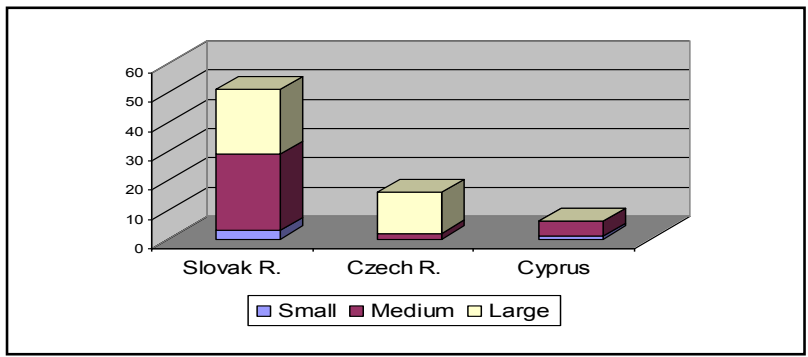

Fig. 1. Categorization of the participating businesses by location and size

From the perspective of the industry represented were automotive, mechanical, chemical, food and electronics industry. 38 companies (representing 52\%) out of the 73 that do not have an ergonomics program implemented, or health and safety program do not have any program at all. The Ergonomics program has 34 enterprises established under the $\mathrm{OSH}$ programs, one company has an ergonomics program introduced separately (together $48 \%$ ). For a clearer picture, see below chart number 2 .

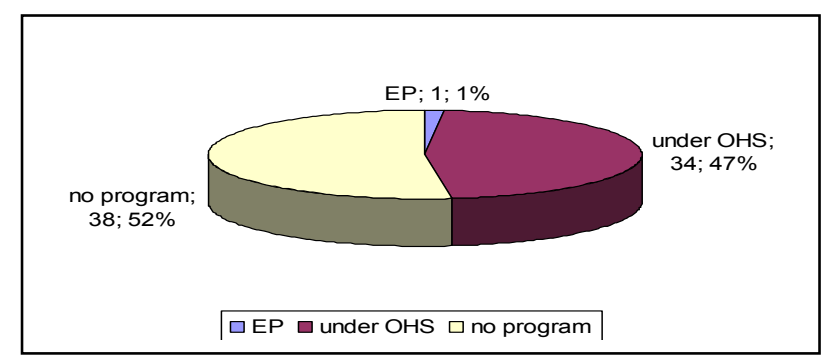

Fig. 2. Company replies to the application questions of the Ergonomics program (EP) 
Enterprises that have an Ergonomics program implemented under the OSH programs usually do not have to create ergonomics teams. Not all companies that reported the introduction of the ergonomics health and safety programs implemented regular ergonomics analysis and subsequent rationalization of work. The condition of the system to implement this program is the ergonomics analysis of work. Therefore, the ergonomics program is deemed to be established only if a scheduled ergonomics analysis is followed by rationalization, which is repeated every year. From this perspective, an ergonomics program has only 25 businesses, representing 34.2\%, specifically, Cyprus - 0 companies, Czech Republic 10 companies (62.5\% of the total 16) and Slovak Republic 15 (29.4\% of the total 51).

Surveyed with a questionnaire and an ergonomics program were links with other processes in the enterprise, the way of successful implementation of an ergonomics program and perceived benefits from the introduction of the EP within the company.

From the perspective of the most frequent answers:

1 Linking EP with other processes in the enterprise.

- EP program established under the OSH 48.6\%.

- Linking the project implementation phase and the process of change, $25.7 \%$.

2 Ways of successful implementation of the EP.

- Modifying the workplace (automation and robotization), $20 \%$.

- Use health and safety audits, $20 \%$.

- With Change Management, $17.2 \%$.

- External consulting firm, $14.3 \%$.

3 The benefits of implementing the EP.

- Reducing the risk of occupational disease, $42.8 \%$.

- Employee satisfaction, $17.1 \%$.

- Reducing the burden of employees, $11.4 \%$.

A questionnaire was incorporated into the light box of the parent company and its impact on the integration of ergonomics program in a subsidiary. Fifty-two companies said they are not subsidiaries. The remaining 21 were foreign parent companies. Twelve of them have introduced the same ergonomic program as their parent company. Of the remaining 9 companies, 6 have established their own ergonomics program. Three companies have not introduced the EP at all.

\section{EVALUATION RESEARCH}

Ergonomics program has introduced separately or under the OSH programs to $52 \%$ of surveyed companies. The rest of enterprises declared the introduction of the EP. It is important to note that not all businesses have indicated the existence of this kind of ergonomics teams had created and regularly analyze the subsequent rationalization of work. In view of the complexity, of the program only $34.2 \%$ of enterprises have implemented ergonomics program systemically.

Most businesses incorporating ergonomics programs under the OSH program provide an ergonomic analysis of safety and health through regular audits. As the perceived advantage, it reduces the risk of occupational disease. Some companies reported cost savings as an advantage. The companies were asked an additional question regarding the practical assessment of the financial savings following the introduction of ergonomics program. None of the companies made this kind of analysis - an evaluation of implementation of the program.

From a perspective, the impact of parent companies to subsidiaries indicated the effect of encouraging the introduction of ergonomics program. However, no parent company always insists on introducing a similar program.

Much of the information is repeated in the questionnaires, but some answers were quite enlightening. Questions 5-6-7 were answered in brief description. Two companies are affiliated with the ergonomics program quality management system. There are three companies which are linked to ergonomics program running ISO 9001 - ISO 14001 - OHSAS 1801 (Quality Management System - Environmental Management - Management of health and safety).

\section{CONCLUSION}

Future process-oriented manufacturing enterprises are the integration of systems (ISO 9001 - ISO 14001 - OHSAS 1801). Penetration of these standards and process management (Závadský J. 2004), linking Environmental management in the enterprise with an ergonomics program is the goal of developing a common orientation to people. One part of environmental management is the protection of workers, work safety and accident prevention threatening a business environment. To restore mental and physical state, man urgently needs suitable conditions and environment. The surrounding environment largely affects the mental and physical balance and human health. The goal of an ergonomic workplace adaptation is continuous maintenance of required job performance and ensuring security and safety at work that is an integral part of providing an acceptable environment (Hatiar K., 2004). Ensuring acceptable environment is not only seen as creating a conducive environment in the workplace, but there is an effort to understand, not damage the environment outside the work environment as inherently important to recover and maintain good health workers. Only a rested, healthy and happy worker may perform work tasks well.

Ergonomics programs advise the management system of health and safety OHSAS 18001 . This standard does not yet deal with programs to improve health. It is only a matter of time, this standard will extend to these programs and ergonomics program will be one of them. Thus, integrated systems should be especially large companies. It would be ideal if the medium-sized businesses have a system of health and safety management, but this standard which is adopted internationally, became the first international standard.

Preservation of human health, the company is building a society-wide recognition, the satisfaction of their staff, and not least, it has a significant impact on economic indicators.

\section{ACKNOWLEDGEMENT}

This work was supported by KEGA - 3-7285_09 Content, Integration and Design University Textbook "Specialized Robotics Systems in Print and Interactive Modules".

\section{REFERENCES}

Cohen, L.C. ; Gjessig, CH.C. ; Fine, L.J.; Bernard, P.B. ; Mcglothlin, J.D. (1997). Elements of ergonomics programs: A Primer Based on Workplace Evaluation of Muskuloskeletal Disorders, Centers for Disease Control and Prevention, NIOSH, Publication No. 97-117, ISBN: 078817-095-3, pp. 133, Columbia Parkway

Hatiar, K. (2004). Ergonomic and preventive ergonomics programs, Institute of Occupational Safety s.r.o., ISBN 808063-113-1, pp. 3-6, Trnava

Hatiar, K. (2010). Ergonomic and legislation, In: Ergononomics 2010 : Progressive methods in ergonomics. Slovak Ergonomic Society, ISBN 978-80-970588-6-9, pp. 33-42, Žilina

Grasseová, M. (2008). Process management in public and private sector, Computer Press, ISBN 978-80-251-1987-7, pp. 62-65, Brno

Závadský, J. (2004). Process management in the practice of the manager, SP Synergia, ISBN 80-98734-8-2, pp. 238, Trnava 